\title{
Effectiveness of Safety Precautions of Medical Bubble Applied During IHF World Cup (Egypt 2021)
}

Ali Mobark Mobark ${ }^{1}$, Ahmed El-Sayed Awaadd ${ }^{2}$

1. Department of Sports Health Science, Faculty of Physical Education, Tanta University, Tanta 31527, Egypt. dr.alimobark@phed.tanta.edu.eg

2. Department of Team\& Racquet Sports, Faculty of Physical Education, Tanta University, Tanta 31527, Egypt. Member of the Committee for Analysis and Statistics at the World Handball Championship Egypt 2021. ahmed.awaadd@phed.tanta.edu.eg

\section{Abstract}

Objectives: To evaluate the effectiveness of the anti-Covid-19 Medical Bubble applied during IHF World Cup (Egypt 2021).

Design: The researchers applied the descriptive (survey) approach due to the nature of this study on a group including (31) personnel.

Methods: The researchers applied "Effectiveness of Medical Bubble Measures" e-Questionnaire to (31) members representing (27) Team Logistic Services Officials (TLOs) and (4) team doctors. As a member of the committee of statistics and analysis during the championship, one researcher recorded direct observation on a daily basis during IHF World Cup (Egypt 2021) concerning the commitment of teams and organizers with medical bubble measures. The researchers sent open-ended questions via e-mail to (8) TLOs of teams sustaining infections during IHF World Cup (Egypt 2021).

Results: (8) teams out of (31) sustained (22) infections with percentage of (2.4\%) out of the total number of participating players $(n=914)$. Teams sustaining most infections were ranked as follows: Switzerland $(19.231 \%)-$ Argentina (14.815\%) - Brazil (12\%) - Macedonia (9.091\%) - Tunisia (10\%) - Slovenia (6.25\%) - Spain (3.704\%) - Chili (3.704\%).

Conclusions: Researchers concluded the effectiveness of medical bubble applied during IHF World Cup (Egypt 2021). Causes of infection were identified and recommendations for improving the medical bubble were discussed.

\section{Introduction:}

By the end of 2019, the whole world was shocked by Corona Virus Disease (COVID-19) pandemic that actually affected all aspects of human activity on Earth. On March $11^{\text {th }} 2020$, WHO announced Corona Virus as a global pandemic. Restrictions imposed over daily life activities to face the massive outbreak of the pandemic directly affected public and private lives and led to the biggest economic crisis all over the world because of the stop of all types of human production due to the complete blockage of whole countries and restricting the movement of millions of people as most of them had to remain in their homes and commit themselves with safety precautions in the face of the pandemic. This was the biggest shock for world economy for decades and its consequences are still under estimation and may continue for years or even decades. IMF projects shrunk with more than $3 \%$ and this is even worse than what happened during the global financial crisis of 2008-2009 ${ }^{(7)}$.

Economically, tourism, catering, entertainment and sport - especially professional sports - are the most affected sectors in a negative way as these sectors, due to its very nature, require gathering of human crowds to sustain profitability. But social; distancing measures imposed over millions of people led to nearly a complete stop of these sectors that sustained massive financial loses that may not be restored before several years ${ }^{(26)}$.

One of the negative effects on Sports industry was the cancelling of many international events in several sports in addition to the stop of professional leagues in many countries and nearly in all sports. This negative effect extended to include training activities of many professional and amateur athletes and ordinary people with athletic aptitudes for fear of infection or increasing the outbreak. Furthermore, Tokyo Olympic Games, intended to be held in 2020, was postponed to 2021 and now it is facing a vague destiny as some call for cancellation while 
others call for holding the Games under strict precautions that may prevent audiences from attending the Games for the first time in the history of Modern Olympics ${ }^{(20)}$.

Some studies indicated that stopping sports activities due to COVID-19 pandemic had major psychological effects over athletes. One study included (800) athletes, (558) coaches and (310) sports managers applied the IES-R and indicated that $34.4 \%$ of participants suffered catastrophic decrease in their psychological status while $26.4 \%$ indicated severe effects due to the stop of sports activity ${ }^{(\mathbf{8})}$.

Facing these severe effects, sports bodies tried to find solutions to resume sports activity and avoid its devastating economic and psychological effects. Some researchers tried to find solutions to resume professional leagues, especially in North America ${ }^{(6)}$ and Spain (4), in addition to other individual sports like golf ${ }^{(15)}$ and even tried to reopen recreational sports centers for the public ${ }^{(2)}$.

Other researchers managed to generate a five-stage model for safety return of sports competitions according to safety precautions as follows:

- Stage one: individual or group training with social distancing.

- Stage two: general training for teams and groups with safety precautions

- Stage three: domestic competitions without crowds

- Stage four: cross-border competitions without crowds

- Stage five: complete competition with crowds and no limits.

They indicated that health and protective precautions and general global status of the pandemic should be considered ${ }^{(17)}$.

Another group generated a set of clinical recommendations for safe return of sports competitions without any clinical complications for athletes. Athletes were grouped according to their conditions and each group should follow specific medical guidelines to insure safe return of sports competitions. ${ }^{(18)}$.

In spite of these alarming conditions, Egypt managed to host IHF World Cup (Egypt 2021) under supervision of IHF and EHF who were responsible for hosting the competitions in a safe way for all participating delegates according to instructions issued in the IHF "Medical Precautions Plan for COVID-19- Egypt 2021". IHF issued the original plan on October 27th 2020 and amended it on December 3rd 2020. The statement indicated all health precautions that should be taken before and during the competition under the concept of "Medical Bubble" defined as: A bubble concept is applied with the aim of minimizing the transmission of COVID-19 infections before, during and after the World Championship in Egypt. All the stakeholders involved in the World Championship should enter the bubble without any external contact within three days before and throughout the event. In addition, as mentioned in chapter 5.1., all stakeholders travelling to Egypt must isolate themselves from the date of the PCR test (within 72 hours before the arrival date) until arrival to Egypt. ${ }^{(13)}$

(32) Teams participated in the finals of IHF World Cup (Egypt 2021) but only (31) teams completed the competitions after disqualification of "Cape Verd" due to lack of players as (6) of the team players were infected after only one match. The total number of players for qualified teams was (914) which is relatively high. All official bodies responsible for the championship, including EHF, Egyptian Ministry of Youth and Sport and Egyptian Ministry of Health, strictly followed the instructions of IHF concerning organizing and managing the championship. Nevertheless, (8) teams reported positive cases of infection with COVID-19 among its members and all measures were taken. The total number of infections was (22) (nearly $2.4 \%$ of total 
participants) which indicates the effectiveness of Egyptian measures taken to decrease the transmission and prevention of COVID-19 infections. This led the researchers to try to identify the causes behind these infections in addition to evaluating the effectiveness of the "Medical Bubble" and the commitment of all stakeholders as a step towards improving its effectiveness during upcoming International and Olympic events.

The current study aims to evaluate the effectiveness of the anti-COVID-19 Medical Bubble applied during IHF World Cup (Egypt 2021).

The current study tries to answer the following questions:

1. How effective was the anti-COVID-19 Medical Bubble applied during IHF World Cup (Egypt 2021)?

2. What are the causes behind infections with COVID-19 during IHF World Cup (Egypt 2021)?

3. How can the effectiveness of the anti-COVID-19 Medical Bubble applied during IHF World Cup (Egypt 2021) be improved?

\section{Methods:}

This study was designed to collect data using an online survey questionnaire designed by the researchers under the title of "Effectiveness of Medical Bubble Measures". In addition, direct observations of one researcher who was member of the committee of statistics and analysis during the championship. Furthermore, the researchers used structured interviews via internet with officials of teams who sustained infections.

The overall study received ethical approval from Tanta University and all procedures were done in accordance with the Declaration of Helsinki. In addition, chairman of the organizing committee of IHF World Cup (Egypt 2021) approved contacts with delegates

Research community included all teams participating in IHF World Cup (Egypt 2021) that ended all its matches in the championship. This includes (31) teams with total number of (914) members. "Cape Verd" team was excluded due to disqualification as it included only (18) members and sustained (6) infections during their first match. Main sample included (31) members representing (27) Team Logistic Services Officials (TLOs) and (4) team doctors. As a pilot sample for verifying internal consistency and reliability of the online questionnaire, the researchers recruited another (12) members from the same research community and outside the main sample.

One researcher recorded his direct observation about the medical bubble measures. The researchers sent the "Effectiveness of Medical Bubble Measures" electronic questionnaire via email to all participants $(n=31)$. Open-ended questions were sent to (8) participants. All these steps were taken from 21-1-2021 to 10-3-2021. After gathering all data, the researchers prepared it for statistical analysis.

The researchers used SPSS.24 and Microsoft Office Excel to calculate the following nonparametric statistical treatments: Percentages - Correlation Coefficients - Split-Half coefficient Cronbach's Alpha - $\mathrm{CHI}^{2}$

Results:

All teams $(n=31)$ indicated that PCR tests were done in hotels daily and they applied medical precautions to all delegate members. 27 teams indicated that the team doctor was the medical officer. Only (8) teams indicated positive cases of Covid-19 infections.

Only (24) indicated that contact persons were isolated till PCR test results delivered. (29) teams asserted that medical precautions were applied in local transportations and food areas while (30) teams indicated that medical precautions were applied in catering areas and locker rooms and (31) teams asserted that precautions were applied in press conferences. Only (4) 
teams indicated difficulties in contacting IHF headquarters or Medical Commission Coordinators.

As for quarantine, (29) teams indicated that positives cases without symptoms and contact persons while (30) teams indicated that quarantine was applied to positive cases with symptoms.

As for teams sustaining positive cases of Covid-19, Switzerland came first with (5) cases out of (26) players while Argentina came second with (4) cases out of (27) players. Brazil, Macedonia and Tunisia came third with (3) cases each out of (25), (33) and (30) players respectively. Slovenia came sixth with (2) cases out of (32) players. Spain and Chili came last with (1) case each out of (27) players for each team.

Percentages of infection for each team came as follows: Switzerland $(19.231 \%)-$ Argentina (14.815\%) - Brazil (12\%) - Macedonia (9.091\%) - Tunisia (10\%) - Slovenia (6.25\%) - Spain (3.704\%) - Chili (3.704\%). Total number of infections was (22) cases out of (227) players $(9.692 \%)$.

Discussion:

Table (1)

Percentages and $\mathrm{CHI}^{2}$ for Participants' Responses. $\quad(\mathrm{n}=31)$

\begin{tabular}{lcccccc}
\hline \hline \multirow{2}{*}{$\mathrm{S}$} & Item & \multicolumn{2}{c}{ Yes } & \multicolumn{2}{c}{ No } & \multirow{2}{*}{ CHI $^{\mathbf{2}}$} \\
\cline { 3 - 6 } & & $\mathbf{F}$ & $\mathbf{\%}$ & $\mathbf{F}$ & $\mathbf{\%}$ & \\
\hline & How many members of your delegate? & & & & & \\
\hline 1 & Was the team doctor the medical officer? & 27 & 87.097 & 4 & 12.903 & 17.065 \\
\hline 2 & Did you do PCR tests in hotel? & 31 & 100 & 0 & 0.00 & 31 \\
\hline 3 & Did you do PCR tests daily? & 31 & 100 & 0 & 0.00 & 31 \\
\hline \multirow{2}{*}{4} & Did you apply medical precautions for all the delegate members \\
& (doctors, coaches ..etc.) ? & 31 & 100 & 0 & 0.00 & \multirow{2}{*}{31} \\
\hline 5 & Did you have any positive cases during competition? & 8 & 25.806 & 22 & 74.194 & 7.258 \\
\hline & If yes, how many? & & & & & \\
\hline 6 & Did contact persons were isolated till PCR tests delivered? & 24 & 77.419 & 7 & 22.581 & 9.323 \\
\hline 7 & Did local transportations apply medical precautions? & 29 & 93.548 & 2 & 6.452 & 23.516 \\
\hline 8 & Did food areas apply medical precautions? & 29 & 93.548 & 2 & 6.452 & 23.516 \\
\hline 9 & Did catering areas apply medical precautions? & 30 & 96.774 & 1 & 3.226 & 27.129 \\
\hline 10 & Did locker rooms apply medical precautions? & 30 & 96.774 & 1 & 3.226 & 27.129 \\
\hline 11 & Did press conferences apply medical precautions? & 31 & 100 & 0 & 0.00 & 31 \\
\hline 12 & Were there any difficulties in contacting IHF headquarters or Medical & 4 & 12.903 & 27 & 87.097 & 17.065 \\
\hline 13 & Were quarantine measures taken with positive cases without symptoms? & 29 & 93.548 & 2 & 6.452 & 23.516 \\
\hline 14 & Were quarantine measures taken with positive cases with symptoms? & 30 & 96.774 & 1 & 3.226 & 27.129 \\
\hline 15 & Were quarantine measures taken with contact persons? & 29 & 93.548 & 2 & 6.452 & 23.516 \\
\hline \hline
\end{tabular}

$\mathrm{CHI}^{2}$ table value on $\mathrm{P} \leq 0.05=3.84$

Table (1) indicated that $\mathrm{CHI}^{2}$ calculated values were higher than its table value as they ranged from (31) to (7.258). this indicates statistically significant differences in favor of those who answered with (Yes) to all items except for item number (6) as differences were in favor of those who answered with (No). 
Table (2)

Number of Team Members and Percentages of Infections

\begin{tabular}{ccccc}
\hline \hline Country & $\begin{array}{c}\text { Number of } \\
\text { team members }\end{array}$ & $\begin{array}{c}\text { Number of infected } \\
\text { players }\end{array}$ & $\begin{array}{c}\text { Percentage of } \\
\text { infection (\%) }\end{array}$ & Rank \\
\hline Switzerland & 26 & 5 & 19.231 & 1 \\
\hline Argentina & 27 & 4 & 14.815 & 2 \\
\hline Brazil & 25 & 3 & 12 & 3 \\
\hline Macedonia & 33 & 3 & 9.091 & 3 \\
\hline Tunisia & 30 & 3 & 10 & 3 \\
\hline Slovenia & 32 & 2 & 6.25 & 6 \\
\hline Spain & 27 & 1 & 3.704 & 7 \\
\hline Chili & 27 & 1 & 3.704 & 7 \\
\hline \hline
\end{tabular}

Table (2) showed numbers of teams with infections, numbers and percentages of infections in each team and the ranking of infected teams.

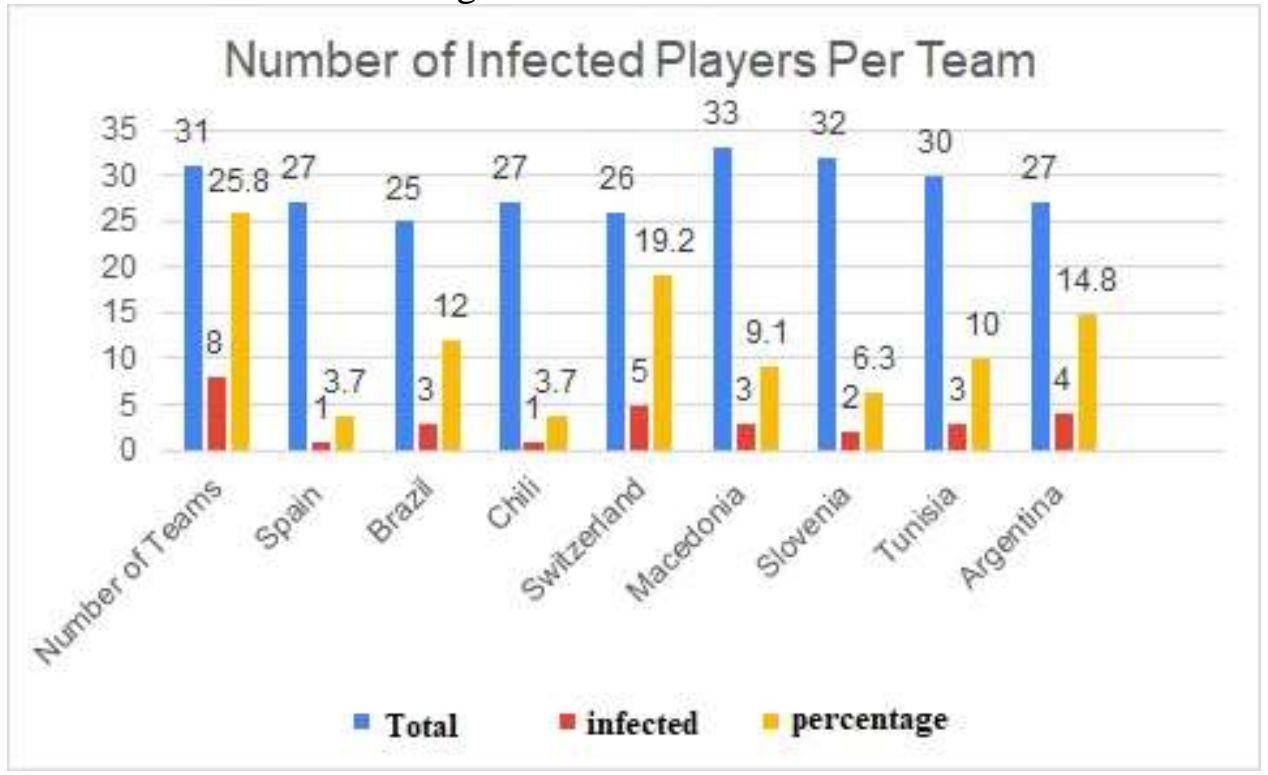

Figure (1)

Numbers and Percentages of Infections in Each Team

Table (1) indicated that PCR tests were done daily in hotels and medical precautions were $100 \%$ applied in press conferences. Team doctors were medical officers for (27) teams. Some teams $(n=4)$ indicated difficulties in contacting IHF headquarters of Medical Commission Coordinator. PCR measures are consistent with previous studies that recommended regular PCR testing to ensure that all athletes are free of infection ${ }^{(5)}(24)$.

As for quarantine, (7) teams indicated that contact persons with positive cases were not quarantined till PCR results while (2) teams indicated that no measures were taken for positive cases without symptoms and one team teams indicated that no measures were taken for positive cases with symptoms. This clearly indicates violations for quarantine measure ignoring recommendations of previous studies and $\mathrm{WHO}$ for quarantining contact persons with positive cases with or without symptoms ${ }^{(21)(22)}$.

Two teams indicated that social distancing measures were not taken in local transportation and food areas while one team indicated that social distancing measures were not taken in catering areas and locker rooms. Previous studies asserted the importance of social 
distancing, self-protection and self-sanitation measures for individuals in mass crowds to decrease and prevent COVID-19 transmission (21) (24)(25)

These results clearly indicated the effectiveness of medical bubble applied during IHF World Cup (Egypt 2021). Mr. Thomas Bach, chairman of the International Olympic Committee, expressed his admiration for the measures taken by IHF that increased the efficiency of the medical bubble ${ }^{(11)}$. Mr. Hassan Mustafa, chairman of IHF, also issued a statement of recognition for the good organization and safety precautions taken by Egypt during the championship ${ }^{(12)}$.

Table (2) and Figure (1) indicated the Switzerland came first with (5) infections (19.231\%) while Chili and Spain came last with one infection each $(3.704 \%)$. Total percentage of infections, based on numbers of team players was $(9.692 \%)$ while the same percentage based on total number of participants was $(2.4 \%)$. This is consistent with IHF statement about number of COVID-19 infections during IHF World Cup (Egypt 2021) ${ }^{(15)}$

In addition, direct observations of one researcher revealed that:

- Statistical reports were delivered manually from the statistics and analysis committee to the main chamber and teams officials during and immediately after the matches.

- Security officers at check points checked transportation drivers without face masks and approached drivers to a non-safe distance.

- EHF chairman, director of the championship, violated the medical bubble several times and the IHF issued a statement of suspending him for this massive violation ${ }^{(14)}$.

- Some teams ordered special meals from outside the hotels.

- Some members of the organizing committee didn't commit to PCR testing as scheduled and didn't follow-up such violations.

This is clearly consistent with violations stated by TLOs in their responses.

In addition, TLOs of infected teams indicated some difficulties and violations for the medical bubble as follows:

- There were difficulties in contacting medical teams.

- Some teams didn't commit to daily PCR testing and some of them did it only every 72 hours.

- Food areas were violated as some teams ordered food from outside the hotels and catering staff was not fully committed to the medical bubble.

- Infrastructure of some hotels was not sufficient for quarantining positive cases.

- Some positive cases were not quarantined.

- Some positive cases were not transported to hospitals and only treated in hotels.

- Sanitation measures for catering areas and locker rooms were not taken seriously.

These violations are consistent with violations recorded by one researcher. These results are totally consistent with previous studies. One study indicated that social distancing was the major mitigator in the Italian case of fighting COVID-19(3), while other researcher indicated that non-compliance with social distancing and self-isolation led to more infections ${ }^{(19)}$. Another study asserted that compliance with self-isolation, self-sanitation, wearing masks and social distancing had direct effects on the pandemic status in USA ${ }^{(1)}$.

Measures taken for isolating infected cases and contacts are of major significance as one study asserted that controlling the spread of infection starts with isolating infected cases and contacts ${ }^{(9)}$. Another study indicated that isolation should not be limited to positive cases as some carriers may not exhibit symptoms but are still infectious ${ }^{(10)}$.

\section{Conclusions:}

According to this study aim, questions, methods and results, the researchers concluded 
the following:

- The medical bubble applied during IHF World Cup (Egypt 2021) was highly effective with infection percentage of $(2.4 \%)$. This means that the bubble was effective by $(97.6 \%)$ in preventing the transmission of COVID-19.

- The following are the reasons behind infections among participants:

* Lack of full commitment with medical precautions inside food areas.

* Lack of full commitment with medical precautions inside catering areas.

* Lack of full commitment with medical precautions inside locker rooms.

* Lack of full commitment with medical precautions inside local transportations.

* Personal violations from some organization officials and some team officials.

- It is necessary to impose full commitment with all medical precautions of the medical bubble from all stockholders without any exceptions and under all conditions.

Technical Implications:

- Our results assert that full commitment with all medical precautions of the medical bubble from all stockholders without any exceptions and under all conditions is required to guarantee the effectiveness of medical bubble measures.

- Hotels with high capacity should be considered when choosing hotels to find enough rooms for quarantine in case of infections for positive cases and contact persons as well.

- It is clear that one doctor per team is not sufficient. Therefore, it is highly recommended to increase the number of authorized doctors to at least four.

- High-tech methods, including e-reports, e-statistics, mobile apps and other means, should be considered to minimize the chance of direct contact among stakeholders.

\section{Conflict of interest:}

No conflict of interest is apparent for this research.

\section{Funding:}

This research was completely funded by researchers without any financial aids from any third party.

\section{Acknowledgment:}

The researchers wish to thank the organizing committee of IHF world cup (Egypt 2021), Charmian Of the Egyptian Handball Federation and all participants in this research for their efforts during the preparation of this paper.

\section{References:}

1. Abouk, R., \& Heydari, B. (2021). The immediate effect of COVID-19 policies on social-distancing behavior in the United States. Public Health Reports, 136(2), 245-252.

2. Blocken, B., Van Druenen, T., Van Hooff, T., Verstappen, P. A., Marchal, T., \& Marr, L. C. (2020). Can indoor sports centers be allowed to re-open during the COVID-19 pandemic based on a certificate of equivalence? Building and environment, 180, 107022.

3. Briscese, G., Lacetera, N., Macis, M., \& Tonin, M. (2020). Compliance with COVID-19 socialdistancing measures in italy: the role of expectations and duration (No. w26916). National Bureau of Economic Research.

4. Buldú, J. M., Antequera, D. R., \& Aguirre, J. (2020). The resumption of sports competitions after COVID-19 lockdown: the case of the Spanish football league. Chaos, Solitons \& Fractals, 138, 109964.

5. Ciotti, M., Angeletti, S., Minieri, M., Giovannetti, M., Benvenuto, D., Pascarella, S., ... \& Ciccozzi, M. (2019). COVID-19 outbreak: an overview. Chemotherapy, 64(5-6), 215-223.

6. DiFiori, J. P., Green, G., Meeuwisse, W., Putukian, M., Solomon, G. S., \& Sills, A. (2021). Return to sport for North American professional sport leagues in the context of COVID-19. British Journal of 
Sports Medicine, 55(8), 417-421.

7. Drewes, M., Daumann, F., \& Follert, F. (2021). Exploring the sports economic impact of COVID-19 on professional soccer. Soccer \& Society, 22(1-2), 125-137.

8. Fiorilli, G., Grazioli, E., Buonsenso, A., Di Martino, G., Despina, T., Calcagno, G., \& Di Cagno, A. (2021). A national COVID-19 quarantine survey and its impact on the Italian sports community: Implications and recommendations. Plos one, 16(3), e0248345.

9. Hellewell, J., Abbott, S., Gimma, A., Bosse, N. I., Jarvis, C. I., Russell, T. W., ... \& Eggo, R. M. (2020). Feasibility of controlling COVID-19 outbreaks by isolation of cases and contacts. The Lancet Global Health, 8(4), e488-e496.

10.Hsiang, S., Allen, D., Annan-Phan, S., Bell, K., Bolliger, I., Chong, T., ... \& Wu, T. (2020). The effect of large-scale anti-contagion policies on the COVID-19 pandemic. Nature, 584(7820), 262-267.

11.https://www.ihf.info/competitions/men/308/27th-ihf-mens-world-championship 2021/22415/news/26979

12.https://www.ihf.info/competitions/men/308/27th-ihf-mens-world-championship2021/22415/news/26977

13.https://www.ihf.info/media-center/news/covid-19-medical-precaution-plan-egypt-2021-updated

14.https://www.ihf.info/media-center/news/statement-suspension-egyptian-handball-federation-presidenteng-hisham-nasr

15.https://www.ihf.info/competitions/men/308/27th-ihf-mens-world-championship2021/22415/news/26455

16. Huth, C., \& Billion, F. (2021). Insights on the impact of COVID-19 and the lockdown on amateur golfers. Quality in Sport, 7(1), 7-19.

17.Kemp, S., Cowie, C. M., Gillett, M., Higgins, R., Hill, J., Iqbal, Z., ... \& Calder, J. (2021). Sports medicine leaders working with government and public health to plan a 'return-to-sport' during the COVID-19 pandemic: the UK's collaborative five-stage model for elite sport. British Journal of Sports Medicine 2021;55:4-5.

18.Löllgen, H., Bachl, N., Papadopoulou, T., Shafik, A., Holloway, G., Vonbank, K., ... \& Pitsiladis, Y. P. (2021). Infographic. Clinical recommendations for return to play during the COVID-19 pandemic. British Journal of Sports Medicine, 55(6), 344-345.

19.Pedersen, M. J., \& Favero, N. (2020). Social Distancing during the COVID-19 Pandemic: Who Are the Present and Future Noncompliers?. Public Administration Review, 80(5), 805-814.

20.Raiola, G., \& Di Domenico, F. (2021). Physical and sports activity during the COVID-19 pandemic. Journal of Physical Education and Sport, 21, 477-482.

21.Salzberger, B., Glück, T. \& Ehrenstein, B. Successful containment of COVID-19: the WHO-Report on the COVID-19 outbreak in China. Infection 48, 151-153 (2020).

22.Tuite, A. R., Ng, V., Rees, E., \& Fisman, D. (2020). Estimation of COVID-19 outbreak size in Italy. The Lancet. Infectious Diseases, 20(5), 537.

23.Update on COVID-19 cases at Egypt 2021, 19 Jan. 2021 https://www.ihf.info/competitions/men/308/27th-ihf-mens-world-championship2021/22415/news/26455

24.Wu, Y. C., Chen, C. S., \& Chan, Y. J. (2020). The outbreak of COVID-19: an overview. Journal of the Chinese medical association, 83(3), 217.

25.Yang, Y., Shang, W., \& Rao, X. (2020). Facing the COVID-19 outbreak: What should we know and what could we do?. Journal of medical virology, 92(6), 536-537.

26.Zinecker, M., Doubravský, K., Balcerzak, A. P., Pietrzak, M. B., \& Dohnal, M. (2021). The COVID19 disease and policy response to mitigate the economic impact in the EU. Technological and Economic Development of Economy, 1-21. 